\title{
Sci-Hub, a challenge for academic and research libraries
}

\author{
Llarina González-Solar; Viviana Fernández-Marcial
}

How to cite this article:

González-Solar, Llarina; Fernández-Marcial, Viviana (2019). "Sci-Hub, a challenge for academic and research libraries". El profesional de la información, v. 28, n. 1, e280112.

https://doi.org/10.3145/epi.2019.ene.12

Article received on 26-09-2018

Approved on 24-11-2018

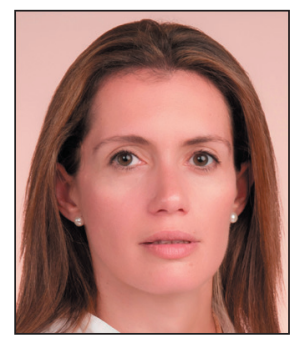

\section{Llarina González-Solar $\bowtie$ \\ https://orcid.org/0000-0003-4443-4102}

Universidade da Coruña (Spain)

Grupo de Investigación Historia, Arqueología,

Documentación y Cultura (Hadoc)

Ilarina.gonzalez@udc.es

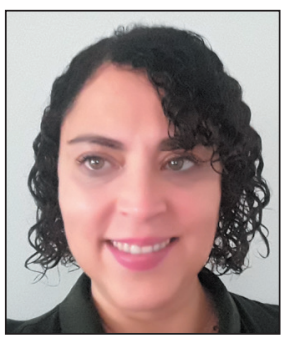

Viviana Fernández-Marcial

https://orcid.org/0000-0002-9277-266X

Universidade da Coruña (Spain)

Facultad de Humanidades y Documentación

viviana.fernandez@udc.es

\begin{abstract}
Sci-Hub emerged into the field of scientific communication in 2011 as a platform for free access to scientific papers. It is the most popular of the so-called shadow libraries, systems that overcome the limits of legal access to scientific publications, standing apart from the open access movement. Besides from the media coverage that has served to boost its popularity, several studies reveal the impact of Sci-Hub among researchers, who have embraced this initiative. Sci-Hub has revealed new forms of access to scientific information, affecting academic and research libraries that cannot remain on the sidelines. This study addresses the Sci-Hub phenomenon and its implications for academic and research libraries from different points of view, through a bibliographic review and an analysis of examples of action.
\end{abstract}

\section{Keywords}

Academic libraries; University libraries; Shadow libraries; Information behaviour; Sci-Hub; Scientific communication; Ethics; Legality; Legal issues; Information access; Open access; Free information; Information usage habits.

\section{Introduction}

In recent years, access to scientific publications has become a battleground, with recurrent reports of scientific and academic entities announcing the cancellation or modification of subscriptions to important publishers. The fundamental cause of this situation can be found in difficulties faced by libraries in meeting ever-growing subscription costs (Piwowar et al., 2018).

Access to scientific content is uneven. Thus, only a small proportion of the world's population has access to most publications, with small institutions in developing countries in the least favourable position (Kirsop; Chan, 2005; Meadows, 2015; Bendezú-Quispe et al., 2016). The open access (OA) movement was born precisely to guarantee access to scientific publications for all, including those who could not afford to pay for them. After years of work, significant advances have been achieved, but the most recent calculations estimate that only a quarter of scientific literature is free of paywalls, in open access (Khabsa; Giles, 2014; Piwowar et al., 2018; Bosman; Kramer, 2018), although the proportion is higher when referring to publications in recent years (Himmelstein et al., 2018; Piwowar et al., 2018).

It is in this context that pirate websites such as Aaaaarg and Library Genesis appear, ignoring or circumventing intellectual property restrictions (Lawson, 2017). Sci-Hub is the best known of all these shadow libraries (Gardner; McLaughlin; Asher, 2017) and probably the most widely used, not only because of the volume of publications to which it gives access, but also because it has received unprecedented attention from both the mass media and academia. 
Academic and research libraries are the traditional providers of scientific information to users which once went, in person, to consult journals (Sathe; Grady; Giuse, 2002). Today, most have chosen to access electronic publications and users have moved to this system (Tenopir et al., 2009). Over the past decades the price of subscriptions has been continuously increasing (Larivière; Haustein; Mongeon, 2015), and the contract models imposed since the 1990s, the big deals, have proved to be excessively rigid and costly in the long term (Sparc, 2018). As a result, research libraries are in a complex position in relation to pirate websites, as the services with which they compete, such as interlibrary loan, have greatly improved, but they cannot provide the level of immediacy of the former. Moreover, experience shows that libraries continue to be where users turn to in order to seek advice and guidance on sources of information, as demonstrated by the development of research support services in many universities (Fernández-Marcial; Costa; González-Solar, 2016), and they must be prepared to face information queries on these illegal systems.

Since Sci-Hub has entered the panorama of access to scientific information, it has generated changes in the consumption of scientific information and has been a turning point for libraries. Crissinger (2017) considers that there is evidence that an analysis of Sci-Hub, from an ethical, technological, intellectual property and inequality point of view, is now a mature topic for debate. The objective of this paper is to describe the various facets of Sci-Hub in order to give as complete a picture as possible of this phenomenon and to assess its impact on university libraries.

\section{Sci-Hub. The new Napster?}

It is not uncommon to find comparisons between Sci-Hub ${ }^{1}$ and the P2P phenomenon that radically changed the music industry at the beginning of the $21^{\text {st }}$ century and which, beyond its own history of growth, popularity and decline, helped to shape the new path that record companies are following today with streaming services as major protagonists. A brief analysis of the history and characteristics of Sci-Hub allows us to understand if its possible final effect on the publishing system will have any parallelism with Napster's.

Sci-Hub's story has its own mythology. Neuroscientist Alexandra Elbakyan, at the tender age of 22, created Sci-Hub, which was released on September 5, 2011. This was her response to difficulties in accessing scientific publications after her return to Kazakhstan. At that time, the options available to circumvent the paywalls were to write directly to the authors of the publication or to request the document via Twitter with the hashtag \#IcanhazPDF, in the hope that someone with access could send a copy (Bonhanon, 2016a; 2016b; Himmelstein et al., 2018).

Its implementation has been growing over the past seven years, as has the media attention it has received, with Elbakyan being named among "Nature's 10: Ten people who mattered this year" in December 2016 as milestone. Both legal battles and articles written about Sci-Hub or Elbakyan (and their consideration among "Nature's 10") make them trending on Google searches (Himmelstein et al., 2018). In other words, every time Sci-Hub and/or its creator are the object of media attention, even if it is from a critical position or a company demands it, a significant amount of free publicity is generated.

But what is Sci-Hub, and how does it work? To start with, it can be classified in a number of ways: as an online search engine, a web page, or as a collection of academic articles. Elbakyan (2017) describes it as follows:

"The core of Sci-Hub is a script that downloads html and pdf pages from the Web. In that sense, Sci-Hub is technically more similar to a web scraper [...] Sci-Hub technically is by itself a repository, or a library if you like, and not a search engine for some other repository. But of course, the most important part in Sci-Hub is not a repository, but the script that can download papers closed behind paywalls".

The creator of Sci-Hub does not offer explanations on how it obtains the papers hosted in the repository. Bonhanon (2016b) indicates that this harvesting of documents involves collecting user data to overcome payment barriers; access credentials can be obtained by voluntary contributions from researchers or through unethical methods, such as phishing emails, as stated by publishers. Elbakyan (2018) does not reveal the origin of the accounts it uses but indicates that they come from various sources, including some illicit ones.

In order to maintain access to this information, it uses a succession of mirror sites, as do other pirate information systems such as The Pirate Bay (Penn, 2018) using a decentralized scheme that is difficult to control and has a wide international scope. It has a bot for Telegram users (@scihubot) although the most frequent way to access Sci-Hub is through its web page which, due to lawsuits, has been deftly and repeatedly changing its domain name, and has been hosted in various countries (Laos, Hong Kong, Mongolia, Taiwan, Russia..., among others) and in Tor (The Onion Router).

Over the years multiple attempts have been made to quantify the number of documents collected by Sci-Hub and their coverage. It is estimated that it contains $69 \%$ of the scientific articles with DOI, of which 54.5 million articles are for payment and account for $85.1 \%$ of the total number of articles behind paywall (Himmelstein et al., 2018). These data correspond to the documents that have already been downloaded to its repository, not to those that could be accessed on demand whose 
number would be substantially higher. Greshake (2017) estimates that $95 \%$ of these publications are subsequent to 1950 despite having some as old as the 1619 edition of the book Descriptio cometæ. Its size would represent a real threat to the current model of scientific publication and, in particular, to payment by subscription (McKenzie, 2017).

In terms of coverage, Houle (2017) detects variances between disciplines, with less presence of law, music and some areas of economics; and Himmelstein et al. (2018) highlight the strong presence of chemistry and health sciences. Most of the documents contained are journal articles for which it represents $77.8 \%$ of what is present in Crossref. This high coverage rate is also shown in contributions to congresses $(79.7 \%)$ and is very limited in other types of documents such as book chapters (14.2\%) or standards (1.5\%) (Himmelstein et al., 2018).

\section{Who uses Sci-Hub and how?}

The above data demonstrate the magnitude of Sci-Hub as an information resource. The key question then arises, who uses it? Bearing in mind that its objective would be to facilitate access to scientific literature for those who cannot afford it because of its high cost.

Regarding the intensity of Sci-Hub use, Van-Noorden (2016) reports a number of downloads exceeding 75 million in 2016 (surpassing 42 million in 2015), which represents 3\% of all downloads of this type of publication worldwide. Documents after 1985 account for $95 \%$ of downloads, and 35\% are less than two years old at the time of download (Greshake, 2017). Their growth appears to be soaring, reaching 88\% per year (Himmelstein et al., 2018).

As to Sci-Hub utilization data (2015-2016), Bonhanon (2016b) estimates, not without surprise, that a quarter of the requests for articles come from rich countries, presumably without problems of access from their institutions,

"in fact, some of the most intense use of Sci-Hub appears to be happening on the campuses of U.S. and European universities" (p. 510).

However, his data show that the countries with the highest volume of downloads to be, in the following order: Iran, China, India and Russia. Greshake (2016) detects an intensive use in Portugal, Iran, Tunisia and Greece; Himmelstein et al. (2018) affirm that preferential use is occurring in countries with lower access capacity through institutional channels.

The reason for these variations and the impact on specific campuses could be related to the growth of text mining techniques, which require a large volume of text to work with and which, unlike automatic downloads at Sci-Hub, are very costly to obtain through the usual services in terms of time spent. Some countries such as Iran (where national legislation permits) appear to be making national mirrors (Bonhanon, 2016b).

In early 2018, Sci-Hub posted full data for $2017^{2}$ on Twitter. An analysis of these using the OpenRefine tool allows us to affirm that many of these trends are maintained today. It is confirmed that among the countries with the highest downloads we have emerging powers such as China, India or Brazil, atypical cases such as Iran and also countries with highly developed economies and research structures such as the USA or France (Figure 1). These data should be studied in the future taking into account correction and weighting factors such as the number of researchers, research centres, investment in science, etc.

Raw usage data for the months of September 2015 to February $2016^{3}$ show that Spain accounted for an average of $1.5 \%$ of total Sci-Hub downloads worldwide, with some concentration of IP in the main research poles. The data corresponding to 2017 show a certain increase in downloads, so that Spain represents $2.04 \%$ (a total of 3,089,349), occupying position 11 in this peculiar ranking. There is some correspondence between the areas with the highest downloads in the

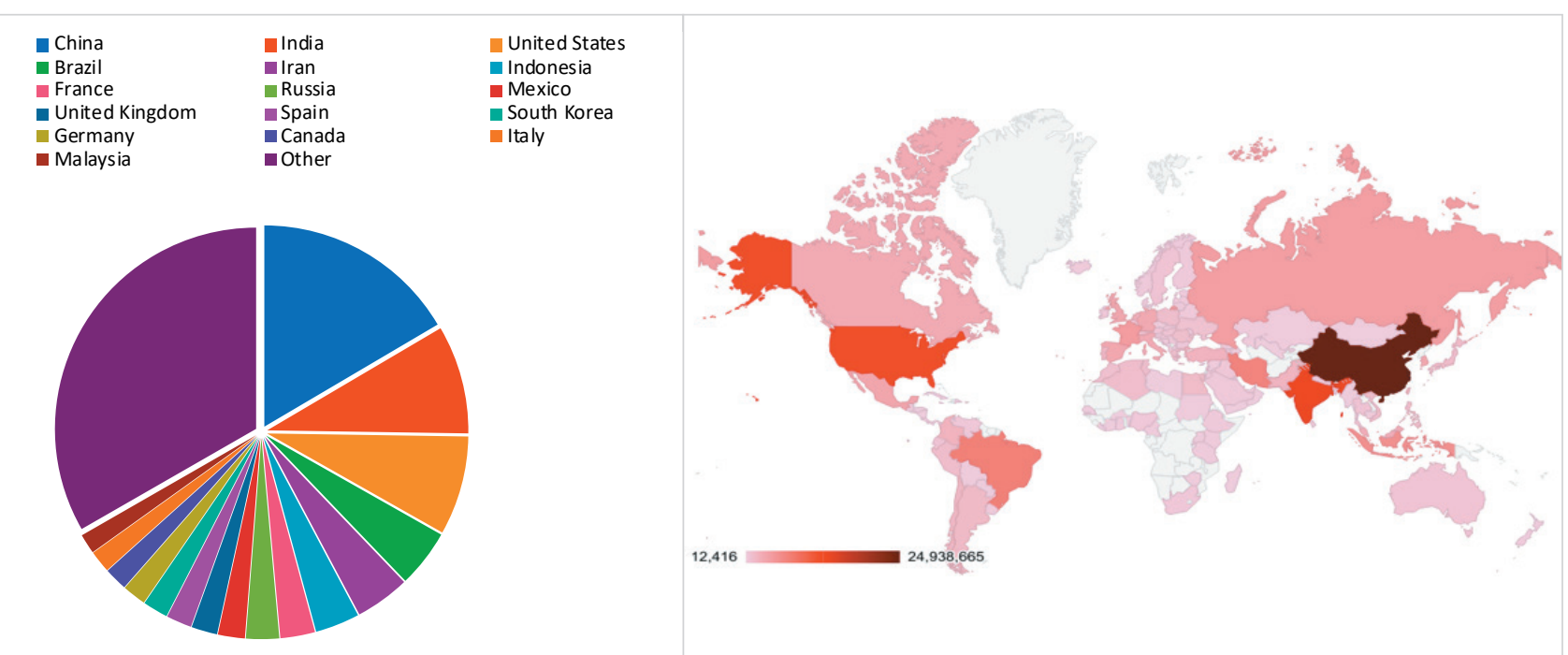

Figure 1. Distribution by country of Sci-Hub downloads and details of countries with more than $1.5 \%$ of the total 
data for 2015-2016 and those for 2017 (Table 1), with large cities with consolidated university campuses having the highest incidence, and Madrid having nearly twice as many downloads by 2017 as Barcelona. The articles with the highest number of downloads in Spain show a preference for the areas of health sciences, sciences and engineering and with a greater presence of articles subsequent to the year 2000 .

Faced with this ubiquity of downloads, it is worth asking the reasons for them. In those countries where access is limited due to the scarcity of economic resources, the answer is simple: in order to do science, access to scientific contents is needed and this is the only possible way for articles that are not in open access, avoiding any payment.
Table 1. Spanish cities with the highest number of Sci-Hub downloads

\begin{tabular}{|l|l|c|l|c|}
\hline \multirow{2}{*}{ Position } & \multicolumn{2}{|c|}{ 2015-21064 } & \multicolumn{2}{c|}{2017} \\
\cline { 2 - 5 } & \multicolumn{1}{|c|}{ City } & Downloads & \multicolumn{1}{c|}{ City } & Downloads \\
\hline 1 & Madrid & 98.143 & Madrid & 868.322 \\
\hline 2 & Barcelona & 78.535 & Barcelona & 488.101 \\
\hline 3 & Valencia & 26.634 & Valencia & 215.690 \\
\hline 4 & Bilbao & 12.622 & Sevilla & 72.613 \\
\hline 5 & Zaragoza & 10.795 & Bilbao & 67.899 \\
\hline 6 & Santander & 10.377 & Zaragoza & 61.313 \\
\hline 7 & Murcia & 8.819 & A Coruña & 60.267 \\
\hline 8 & A Coruña & 8.360 & Murcia & 54.065 \\
\hline 9 & Sevilla & 7.432 & Valladolid & 40.853 \\
\hline 10 & Oviedo & 7.406 & Alacant & 40.040 \\
\hline
\end{tabular}

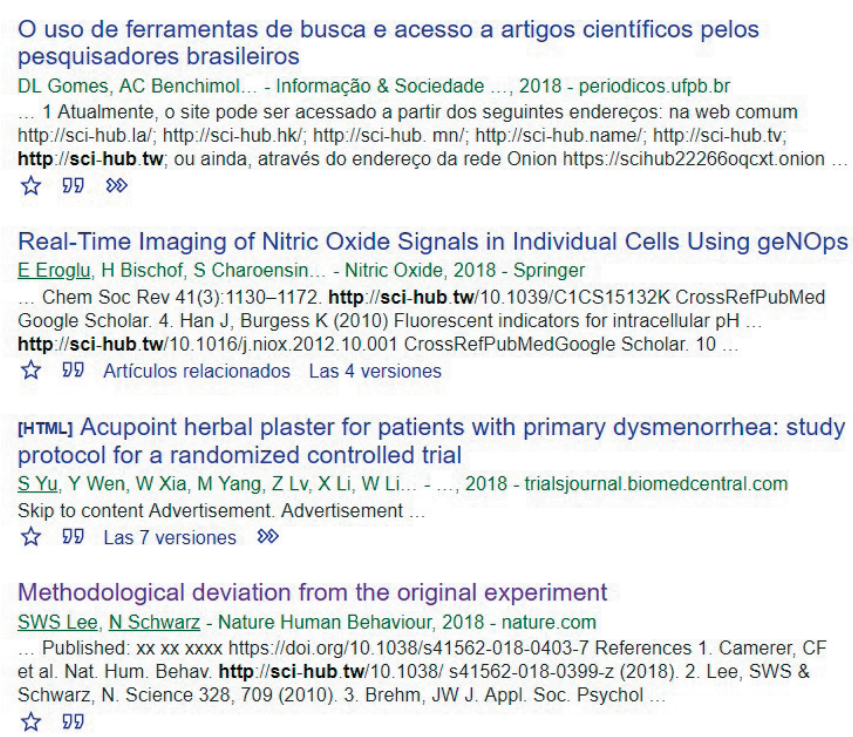

Figure 2. Google Scholar search that exemplifies the lack of knowledge about Sci-Hub, used when referencing bibliographic citations. Source: Google Scholar

This justification is, however, insufficient as it cannot be applied to the United States or Europe. A survey published in Science attempts to discover the underlying reasons: researchers claim lack of access to documents (50\%), disagreement with editing and publication models (23\%) and convenience (17\%) (Travis, 2016). For countries with good access Bonhanon (2016b) focuses on two possible reasons: confusion about what $\mathrm{Sci}$ Hub is (Figure 2) and convenience.

\section{The debate of morality}

Elbakyan has justified the creation and maintenance of Sci-Hub as illegal but ethical, arguing that the concept of property and intellectual property are unnecessary, communism or theft as a fundamental element for the advancement of science... and comparing its creation with the acts of characters such as Robin Hood or Hermes (Figure 3).
[PDF] ufpb.br

[HTML] biomedcentral.com

\section{Theft! a small protest against property striving for equality}

- Robin the Hood

- Hong Gildong

- Ishikawa Goemon

- Алдар-Косе

- Hermes Greek god ...

government taxation system?

Sci-Hub fits 'natural law'

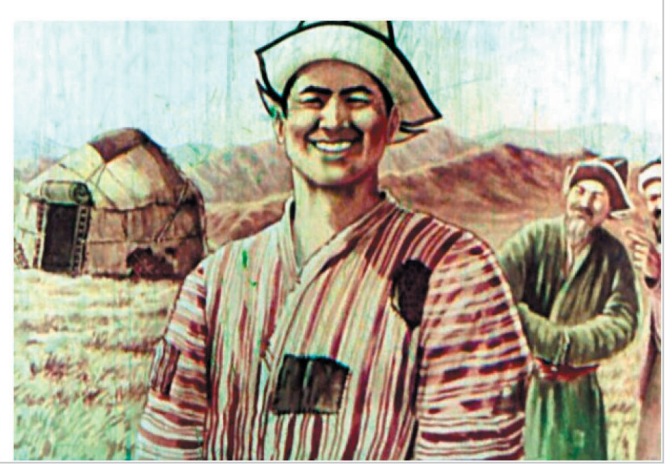

Figure 3. Example of Elbakyan's (2016) discourse developed in her presentations. 
In this debate, which Triggle and Triggle (2016, p. 6) summarize by asking "Is Sci-Hub altruism or copyright theft?" One can see the opinions of different groups, which must be confronted. Obviously on one side are the publishers and, at the opposite extreme, Elbakyan. In addition, the opinion of researchers should be valued. They use Sci-Hub extensively $(60 \%)$ and think that using it is not incorrect (88\%), according to the Science survey (Travis, 2016). Among people who study SciComm or scientific publication as a process, the debate has been very intense and has spread in recent years over news, forums, blogs and scientific literature (Machin-Mastromatteo; Uribe-Tirado; Romero-Ortiz, 2016; McNutt, 2016; Priego, 2016; Woolston, 2016).

The central argument of support for Sci-Hub lies in the inequality of the scientific publishing system and in considering that the fundamental objective of changing it and making it fairer requires any means. In this line of thought Sci-Hub may not be the solution but it is a wake-up call as to the need to build a common scientific and academic heritage, beyond the limits imposed by intellectual property (Lawson, 2017). Sci-Hub is a symptom, a reaction to a problem that has to be solved no matter what.

The signatories of the open letter "In solidarity with Library Genesis and Sci-Hub" are signified in the group of people with the greatest affinity for the platform (Custodians Online Campaign, 2015). The largest number of Sci-Hub supporters seem to be in the area of medicine, not only among researchers, but among physicians seeking better alternatives for their patients (Bendezú-Quispe et al., 2016; Faust, 2016; Triggle; Triggle, 2016). This idea is clearly evidenced in Latin America with the positive perception of Sci-Hub among medical students (Mejia et al., 2017) and high download volume data, to which Machin-Mastromatteo et al. (2016) propose to improve access to medical scientific literature especially through the promotion of open access.

Those who look at the phenomenon from a critical perspective point out that the platform infringes laws, being "copyright-breaking on a grand scale" (Van-Noorden, 2016), which is neither admissible nor justifiable, insisting that there are legal alternatives such as open access (Greco, 2017). McNutt (2016) emphasizes other collateral factors such as the loss of usage data and its implication in the management of subscriptions, the repercussions for publishing house workers, the impact on smaller publishing houses such as non-profit scientific societies... We can add to all these the possible and unpredictable consequences for authors.

The relationship between Sci-Hub and OA is controversial. Sci-Hub is generally not considered as part of the OA movement (Piwowar et al., 2018) although in some cases it has been labeled as a subtype of it, following the ideas put forward by the "Guerilla Open Access Manifesto" (Swartz, 2008). Björk (2017) and Penn (2018) call it black open access (together with ResearchGate, Academia.edu, Google, the tag \#icanhazpdf...) considering it one of the greatest challenges to the traditional model of academic publication.

Peter Suber warns that being confused with piracy can have a "strategic cost" for the OA movement (Bonhanon, 2016b) in terms of distorting its purpose and even replacing one paywall with another by reinforcing the golden route (Novo; Onishi, 2017). However, from the ranks of OA there has been explicit support for Sci-Hub (Cochran, 2016) and tweets are frequent in providing their new domains. Heather Piwowar gives it an instrumental role by scaring editors and pushing them to "do the right thing" and bet on open access (Van-Noorden, 2016). There is some consensus that Sci-Hub has generated debate and attracted media attention (Emery, 2016; Van-Noorden, 2016; Novo; Onishi, 2017; Piwowar et al., 2018). De-Castro (2016) even compares Alexandra Elbakyan with the girl in Andersen's tale who pointed out that the emperor has no clothes.

Sci-Hub is attributed the quality of "disruptive" (Bonhanon, 2016b; Emery, 2016; Machin-Mastromatteo et al., 2016; Steel, 2016; Travis, 2016; Himmelstein et al., 2018; Marple, 2018, Nicholas et al., 2018). However, for Priego (2016) the platform does not represent a substantial cultural change, since gratuity does not alter the basis of the current system of scientific communication. To make this assessment, the judgment of time will indicate whether or not the existence of Sci-Hub entails a real change in the model of information consumption and scientific communication.

It is necessary to raise the risks of dependence on a system that is managed by one person. Those who choose to rely on Sci-Hub for their access to science (for whatever reason) are subject to the whims of Elbakyan. A telling example occurred in September 2017 when she brought down the system in Russia for several personal offenses (Travis, 2017).

\section{Sci-Hub: a turning point for libraries}

The emergence of Sci-Hub has signified a turning point for academic and research libraries, representing a challenge for the information retrieval systems offered through them. Sci-Hub's interface is simple and friendly, similar to Google. Users access the content of the document using only the DOI or text title. Faust (2016) relates

\section{Sci-Hub has been a challenge for acade- mic and research libraries and for the information retrieval systems offered through them}

"click burden' using Sci-Hub was substantially lower than going through my hospital's online library, and it saved me many seconds". 
Oakely (2016), who compares a paper search in the Georgetown University Library and Sci-Hub (Figure 4), points in the same direction.

This simplicity is one of its strengths against library models, so it could be emerging as the go-to resource even for journals acquired by libraries (Bonhanon, 2016b). Some publishers even point the finger at libraries for using unfriendly retrieval systems or for not adequately "educating" researchers in them (Bonhanon, 2016b).

Faust (2016) highlights the reliability of the recovery as an aspect in Sci-Hub's favour:

"Sci-Hub's appeal does not rest on speed alone but rather its reliability. Some have observed that finding an article through a hospital or university library doesn't guarantee that the article will actually be available for download. Surely we have all encountered the dreaded "request access" hyperlink for a sought article found in a library's database, a phrase that might as well be synonymous with "fuhgeddaboudit." In contrast, when Sci-Hub finds an article, you're always 1 click away from the pdf file. The appeal quickly becomes clear. Alternatively, of course, there's always Google. By Googling my article, I found that I could rent it for \$6 per day or buy it for \$38. (p. 15A).

Furthermore, Sci-Hub's existence affects the contracting of resources. Steel (2016) points out that libraries do not take decisions such as canceling their licenses due to the availability of articles in Sci-Hub; but it does appear that the existence of these systems, which are still resources that users are already using, is influencing the development of negotiations for the subscription of journals, specifically when it comes to big deals (Esposito, 2017). Other authors such as Strielkowski (2017) consider that the impact of Sci-Hub can lead to a change of business model based on more reasonable prices, although subscriptions would prevail. Himmelstein et al. (2018) study the evolution of contracting, from the hegemony of big deals to their gradual replacement by "à la carte" selections and the recent cancellations of important contracts with Elsevier. The authors observe that this publisher's lawyers already anticipated the possibility that Sci-Hub and LibGen would reach a level at which they could

"serve as a functionally equivalent, although patently illegal, replacement for ScienceDirect" (p. 13).

The possibility has been raised that the existence of Sci-Hub or other academic publication exchange systems may be affecting the use of library services, specifically interlibrary loan (Gardner; Gardner, 2015), however this fact has yet to be demonstrated as there are no reliable data.

Cochran (2016) called into question, from the publishers' perspective, the role of libraries and universities as responsible for the illegitimate use of credentials, breaking licensing agreements and allowing illegal downloading of articles. Watermarks make it possible to know which university each article comes from, which is why he considers universities obliged to prevent this from happening and to reflect their position in codes of conduct. There is some debate about whether libraries can monitor patterns of credential use regularly enough to avoid these deviations, and even whether it may be contrary to their very nature to do so (Ruff, 2016; Russell; Sánchez, 2016; Hoy, 2017).

The ethical and legal aspects surrounding Sci-Hub also place libraries in a new landscape. Librarians debate between defending access to scientific information and the legal implications of its use. There is some latent support among librarians, although few would recommend it openly since, even though they may agree with its objectives or motivations, few would agree with the means it uses (Ruff, 2016; Steel, 2016; Penn, 2018). A good example of this is the diatribe between Gabriel J. Gardner (librarian at California State University) and Thomas H. Allen (president of the Association of American Publishers) about the possibility that the former would have recommended the use of Sci-Hub during a talk with librarians (Reichman, 2016).

\section{Communication about Sci-Hub in libraries}

Beyond the subjective aspects of support or disapproval of Sci-Hub, it is interesting to analyze the real way in which libraries communicate this phenomenon or not. There does not seem to be a homogeneous model of communication about shadow libraries. An exploration of Spanish academic libraries shows that this information is not common on the 
websites themselves, although it can be found on the blogs they use as an informal communication system. It appears as one more piece of news of one more system, gathering the content of an article or report that refers to it or as a complement to information on topics such as open access, as we see, for example, in:
There does not seem to be a homogeneous model of communication about shadow libraries

- Blog Universo Abierto of the Universidad de Salamanca (Figure 5):

https://universoabierto.org/2018/04/02/sci-hub-proporciona-acceso-a-mas-de-dos-tercios-de-todos-los-articuloscientificos-publicados

- Blog Acceso abierto of the Universidad de las Palmas de Gran Canaria: http://bibwp.ulpgc.es/accesoabierto/2017/02/10/sci-hub-tiene-ya-en-torno-a-60-millones-de-articulos-cientificosen-abierto

- BujaBlog of the Universidad de Jaén: https://blogs.ujaen.es/biblio/?tag=sci-hub

- Blog Digitum of the Universidad de Murcia: http://digitum-um.blogspot.com/2016/11/posibles-efectos-de-sci-hub-en-las.html

- Boletín DIB of the Universidad de Extremadura: https://deinteresparaelbibliotecario.wordpress.com

- Canal Biblog of the Universidad Autónoma de Madrid: http://canalbiblos.blogspot.com/2017/06/sci-hub-pierde-la-batalla-frente.html

- Blog Fonseca of the Universidade de Santiago de Compostela: https://busc.wordpress.com/tag/sci-hub

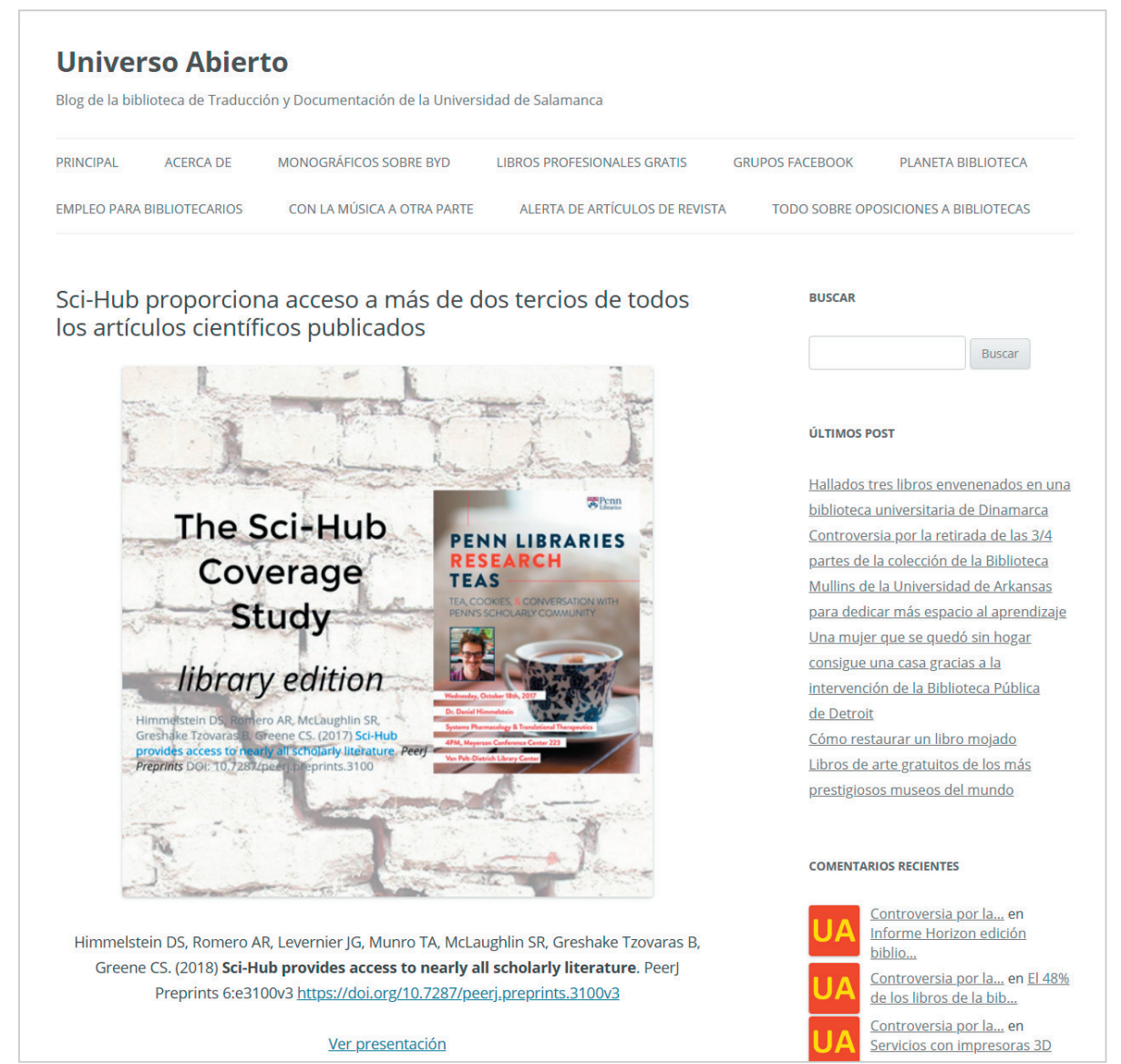

Figure 5. The library blog of the Universidad de Salamanca collects information from an article on Sci-Hub coverage.

In the English-speaking university libraries, however, a greater presence of this information is detected. For instance, Sci-Hub appears in the subject guides of the libraries of the:

- University of Wisconsin-Milwaukee http://guides.library.uwm.edu/scihub 
- University of Delaware https://guides.lib.udel.edu/sci-hub

- Kansas State University https://guides.lib.k-state.edu/c.php?g=645013\&p=4520198

- Washington University in St. Louis https://library.wustl.edu/thoughts-sci-hub-easy-access

- Bond University https://library.bond.edu.au/news/48268/antoinette-cass-manager-scholarly-publications-and-copyright

- University of Windsor

http://leddy.uwindsor.ca/sci-hub-problems-and-questions

And frequently asked questions such as in the Australian Curtin University: https://answers.library.curtin.edu.au/faq/204046

Events such as the symposium "Online piracy: why Sci-Hub is disrupting scholarly publishing" of the Georgetown University Library in $2016^{5}$ or the one entitled "Sci-Hub and LibGen in perspective" at the University of Texas at Austin library in early $2018^{6}$ have also been raised.

Some of this information shows a clear position against Sci-Hub. For example, the Kansas State University library guide states

"This page explains why librarians disagree with using resources accessible from Sci-Hub".

The Bond University Library avoids a clear positioning but reminds that using Sci-Hub or other similar sites is illegal and that its users must abide by the university regulations that also prohibit it.

In several cases, it is insisted from the beginning of the guide that users should not offer their credentials to Sci-Hub, since publishers can act by terminating contracts with the library (Figure $6)$, this information can be supplemented with how to act in case of stolen credentials. Likewise, these guides strive to focus attention on the alternatives offered by the library for obtaining academic information. Less commonly, some libraries such as Cornell Universi$t y^{7}$ report how to use Sci-Hub (Figure 6).

Some libraries have offered to the creator of Sci-Hub a space to communicate her points of view, for example in the framework of the Open access symposium 2016 organized by the University of North Texas Libraries with a presentation titled "Why science is better with communism? The case of Sci-Hub" (Elbakyan, 2016) and available on YouTube; https://youtu.be/hr7v5FF5c8M

Another example is her interven-

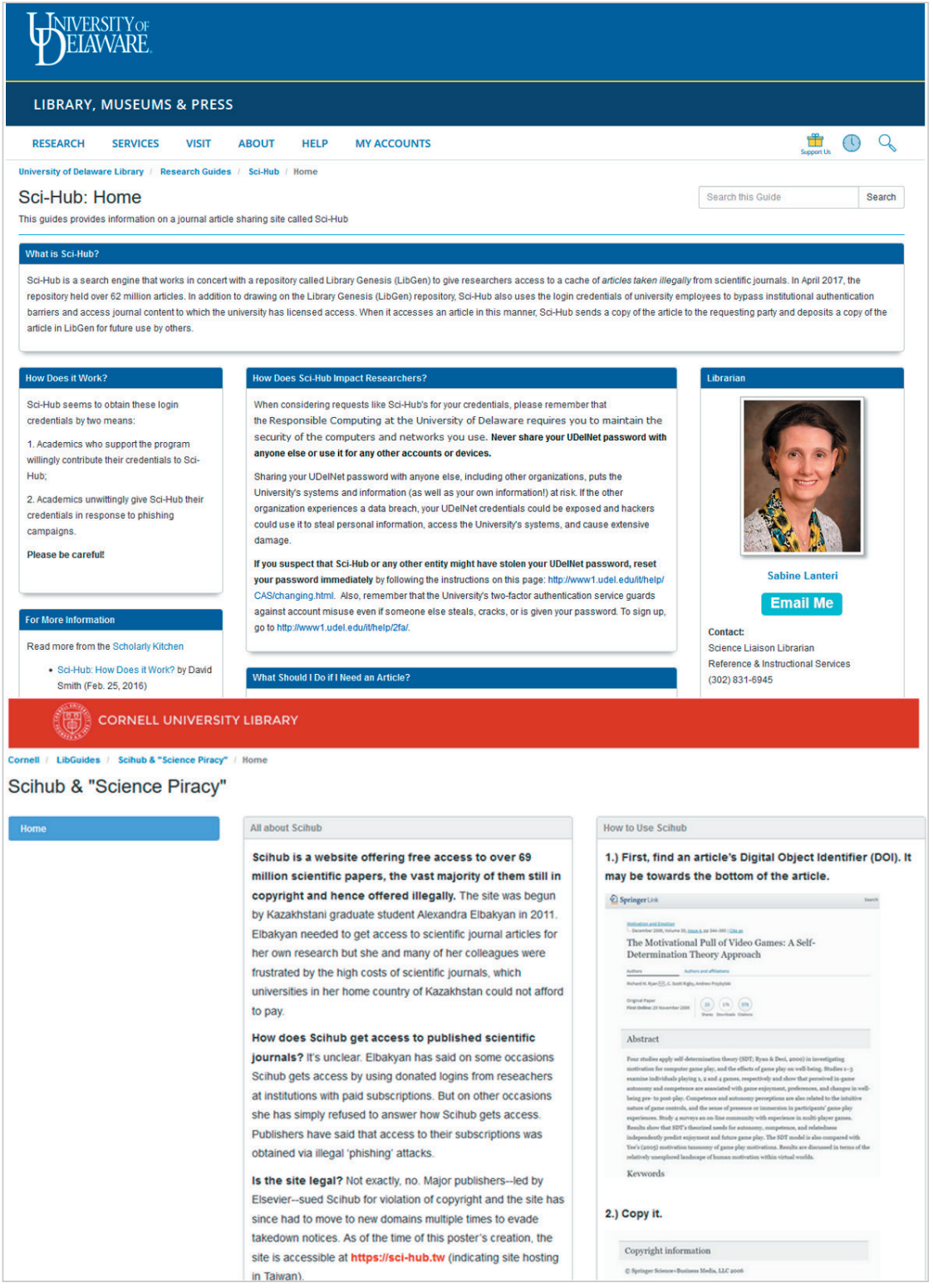

Figure 6. Two different approaches to Sci-Hub from libraries. In the image above the University of Delaware Library Guide warns of the consequences of donating credentials to Sci-Hub and how to act if they have been obtained without authorization. On the bottom, Cornell University's guide explains the use of Sci-Hub without openly positioning for or against it. 
tion in the Workshop for the creation of a network of research libraries held in 2017, a network that belongs to the Ministerio Coordinador de Conocimiento y Talento Humano de Ecuador.

https://youtu.be/w_jc7wNET1Q

\section{Conclusions}

If an anonymous survey or study were carried out among librarians in relation to Sci-Hub, what would be the widespread opinion about its impact and use in libraries? It is evident that the library is a service that, in this context, can have a dual and contradictory vision. On the one hand, it is faced with user demands that can be satisfied with this accessible and unlimited resource and, on the other, with the defense of current hiring models and respect for the ethical use of information, especially from the institutional perspective as a service of research institutions. fore and an after, in an environment that had already been strongly altered by a search engine like Google. As evidence of the impact of the aforementioned search engine on academic activity, we must observe how this company has been creating and generating products that are clearly oriented towards the researcher as a target audience, with Google Scholar being its best exponent. Could the scientific community and information professionals glimpse that citations were going to have a key reference Google Citations?

One of the issues that Sci-Hub has raised is that users, or part of them, prioritize access to scientific content regardless of the legal or ethical connotations that this may imply. This is evident not only in access but also in sharing or disseminating research results. This is a significant change for academic and research libraries because, once again, they face new forms of competition.

The shadow libraries seem to have arrived, perhaps to stay, perhaps to definitively alter the context of scientific communication as Napster did with the distribution of music. Sci-Hub has been the object of this study due to its impact, but there are others, and in the future, new initiatives may be added and, at the moment, we do not know what these may lead to. Librarians can position themselves for or against shadow libraries, from a personal or institutional point of view, but beyond that the truth is that the informational behaviour of researchers can no longer be classified or delimited in a space. Users are the raison d'être of libraries. If they change then....

\section{Notes}

1. For example

- The Washington Post article "Russia is building a new Napster - but for academic research". https://wapo.st/2utfi50?tid=ss_tw-bottom\&utm_term =.b206f3005e50

- Rick Anderson post "Napster vs. Record Labels, Sci-Hub vs. Publishers" in the blog: https://scholarlykitchen.sspnet.org/2018/01/03/napster-vs-record-labels-sci-hub-vs-publishers-part-1-parallels

- Or the papers Crissinger (2017) and Nicholas et al. (2018)

2. Available at $h t t p s: / / t . c o / q d p 7 o N u 2 a y$

3. Available at Dryad: https://doi.org/10.5061/dryad.q447c

4. For this table it is necessary to remember that these data refer only to the period between September 2015 and February 2016, while those corresponding to 2017 refer to the whole year.

5. Whose session can be followed in: https://youtu.be/Qc6PqKlpfkw

6. Information about this event can be found at: https://lib.utexas.edu/events/87

7. This guide, hosted at: https://guides. library.cornell.edu/c.php?g=862841\&p=6185832

was active until mid-September 2018 when it was withdrawn.

\section{References}

Bendezú-Quispe, Guido; Nieto-Gutiérrez, Wendy; Pacheco-Mendoza, Josmel; Taype-Rondan, Alvaro (2016). "Sci-Hub and medical practice: an ethical dilemma in Peru". The lancet global health, v. 4, n. 9, e608.

https://doi.org/10.1016/s2214-109x(16)30188-7 
Björk, Bo-Christer (2017). “Gold, green, and black open access". Learned publishing, v. 30, n. 2, pp. 173-175. https://doi.org/10.1002/leap.1096

Bohannon, John (2016a). "The frustrated science student behind Sci-Hub”. Science, v. 352, n. 6285, p. 51. https://doi.org/10.1126/science.352.6285.511

Bohannon, John (2016b). “Who's downloading pirated papers? Everyone”. Science, v. 352, n. 6285, pp. 508-512. https://doi.org/10.1126/science.352.6285.508

Bosman, Jeroen; Kramer, Bianca (2018). “Open access levels: A quantitative exploration using Web of Science and oaDOI data". PeerJ preprints, 6, e3520v1.

https://doi.org/10.7287/peerj.preprints.3520v1

Cochran, Angela (2016). "A funny thing happened on the way to OA". The scholarly kitchen, 25 February. https://scholarlykitchen.sspnet.org/2016/02/25/a-funny-thing-happened-on-the-way-to-oa

Crissinger, Sarah (2017). "Access to research and Sci-Hub: Creating opportunities for campus conversations on open access and ethics". College \& research libraries news, v. 78, n. 2, pp. 86-95.

https://doi.org/10.5860/crln.78.2.9621

Custodians Online Campaign (2015). In solidarity with Library Genesis and Sci-Hub. http://custodians.online

De-Castro, Pablo (2016). "Breves notas sobre la conferencia anual 2016 de Liber en Helsinki”. Blog EPI, 12 July. http://www.elprofesionaldelainformacion.com/notas/breves-notas-sobre-la-conferencia-anual-2016-de-liber-enhelsinki-pablo-de-castro-liber-open-access-project-officer-miembro-del-grupo-thinkepi

Elbakyan, Alexandra (2016). Why science is better with Communism? The case of Sci-Hub. Presentation. https://digital.library.unt.edu/ark:/67531/metadc850001

Elbakyan, Alexandra (2017). "Some facts on Sci-Hub that Wikipedia gets wrong". Engineuring, 2 July. https://engineuring.wordpress.com/2017/07/02/some-facts-on-sci-hub-that-wikipedia-gets-wrong

Elbakyan, Alexandra (2018). "Corrections to The Verge article about Sci-Hub: part 1". Engineuring, 16 February. https://engineuring.wordpress.com/2018/02/16/corrections-to-the-verge-article-about-sci-hub-part-1

Emery, Jill (2016). "Heard on the net: Open access rhapsody". The Charleston advisor, v. 18, n. 1, pp. 41-42. https://doi.org/10.5260/chara.18.1.41

Esposito, Joseph (2017). "Sci-Hub moves to the center of the ecosystem". The scholarly kitchen, 5 September. https://scholarlykitchen.sspnet.org/2017/09/05/sci-hub-moves-center-ecosystem

Faust, Jeremy S. (2016) "Sci-Hub. A solution to the problem of paywalls, or merely a diagnosis of a broken system?". Annals of emergency medicine, v. 68, n. 1, pp. A15-A17.

https://doi.org/10.1016/j.annemergmed.2016.05.010

Fernández-Marcial, Viviana; Costa, Luis-Miguel; González-Solar, Llarina (2016). "Top universities, top libraries: Do research services in academic libraries contribute to university output?". In: Library Leadership in a Sea of Change, $37^{\text {th }}$ latul Conference, Halifax (Canada).

http://docs.lib.purdue.edu/iatul/2016/spaces/2

Gardner, Carolyn; Gardner, Gabriel (2015). “Bypassing interlibrary loan via Twitter: An exploration of \#icanhazpdf requests". In: ACRL 2015.

http://hdl.handle.net/10760/24847

Gardner, Gabriel J.; McLaughlin, Stephen R.; Asher, Andrew D. (2017). "Shadow libraries and you: Sci-Hub usage and the future of ILL". In: ACRL 2017. http://hdl.handle.net/10760/30981

Greco, Albert N. (2017). "The Kirtsaeng and Sci-Hub cases: The major U.S. copyright cases in the twenty-first century". Publishing research quarterly, v. 33, n. 3, pp. 238-253.

https://doi.org/10.1007/s12109-017-9522-7

Greshake-Tzovaras, Bastian (2016). "Correlating the Sci-Hub data with World Bank indicators and identifying academic use". The winnower, v. 5, e146485.57797.

https://doi.org/10.15200/winn.146485.57797

Greshake-Tzovaras, Bastian (2017). "Looking into Pandora's box: The content of Sci-Hub and its usage". F1000Research, v. 6, n. 541.

https://doi.org/10.12688/f1000research.11366.1 
Himmelstein, Daniel S.; Rodriguez-Romero, Ariel; Levernier, Jacob G.; Munro, Thomas-Anthony; McLaughlin, StephenReid; Greshake-Tzovaras, Bastian; Greene, Casey S. (2018). "Sci-Hub provides access to nearly all scholarly literature". eLife, v. 7, e32822.

https://elifesciences.org/articles/32822

Houle, Louis (2017). "Sci-Hub and LibGen: what if... why not?" In: IFLA WLIC 2017 Libraries. Solidarity. Society, 16-17 August, Gdansk (Poland).

http://library.ifla.org/id/eprint/1892

Hoy, Matthew B. (2017). "Sci-Hub: What librarians should know and do about article piracy". Medical reference services quarterly, v. 36, n. 1, pp. 73-78.

https://doi.org/10.1080/02763869.2017.1259918

Khabsa, Madian; Giles, C. Lee (2014). "The number of scholarly documents on the public web". PLoS one, v. 9, n. 5, e93949.

https://doi.org/10.1371/journal.pone.0093949

Kirsop, Barbara; Chan, Leslie (2005). "Transforming access to research literature for developing countries". Serials review, v. 31, n. 4, pp. 246-255.

https://doi.org/10.1080/00987913.2005.10764998

Larivière, Vincent; Haustein, Stefanie; Mongeon, Philippe (2015). "The oligopoly of academic publishers in the digital era". PLoS one, v. 10, n. 6, e0127502.

https://doi.org/10.1371/journal.pone.0127502

Lawson, Stuart (2017). "Access, ethics and piracy”. Insights. The UKSG journal, v. 30, n. 1, pp. 25-30. https://doi.org/10.1629/uksg.333

Machin-Mastromatteo, Juan D.; Uribe-Tirado, Alejandro; Romero-Ortiz, Maria E. (2016). "Piracy of scientific papers in Latin America". Information development, v. 32, n. 55, pp. 1806-1814.

https://doi.org/10.1177/0266666916671080

Marple, Holly (2018). "Parasite, pirate, and Robin Hood: Sci-Hub is disrupting the world of academic publishing". The journal, v. 3, n. 2.

https://theijournal.ca/index.php/ijournal/article/view/29480

McKenzie, Lindsay (2017). "Sci-Hub's cache of pirated papers is so big, subscription journals are doomed, data analyst suggests". Science news, 27 July.

https://doi.org/10.1126/science.aan7164

McNutt, Marcia (2016). "My love-hate of Sci-Hub". Science, v. 352, n. 6285, pp. 497-497.

https://doi.org/10.1126/science.aaf9419

Meadows, Alice (2015). "Beyond open: Expanding access to scholarly content". The journal of electronic publishing, v. 18, n. 3.

https://doi.org/10.3998/3336451.0018.301

Mejia, Christian R.; Valladares-Garrido, Mario J.; Miñan-Tapia, Armando; Serrano, Felipe T.; Tobler-Gómez, Liz E.; Pereda-Castro, William; Mendoza-Flores, Cynthia R.; Mundaca-Manay, Maria Y.; Valladares-Garrido, Danai (2017). “Use, knowledge, and perception of the scientific contribution of Sci-Hub in medical students: Study in six countries in Latin America". PLoS one, v. 12, n. 10, e0185673.

https://doi.org/10.1371/journal.pone.0185673

Nicholas, David; Boukacem-Zeghmouri, Chérifa; Xu, Jie; Herman, Eti; Clark, David; Abrizah, Abdullah; Rodríguez-Bravo, Blanca; Świgoń, Marzena (2018). "Sci-Hub: The new and ultimate disruptor? View from the front". Learned publishing, 1 November.

https://doi.org/10.1002/leap.1206

Novo, Lluís A. B.; Onishi, Viviani C. (2017). “Could Sci-Hub become a quicksand for authors?”. Information development, v. 33, n. 3, pp.324-325.

https://doi.org/10.1177/0266666917703638

Oakley, Meg (2016). Online piracy: Why Sci-Hub is disrupting scholarly publishing. Georgetown University Library. https://www.library.georgetown.edu/sites/default/files/sci-hub-intro.pdf

Penn, Louise (2018). "Alternative ways of obtaining scholarly articles and the impact on traditional publishing models from a UK/European perspective". Serials review, v. 44, n. 1, pp. 40-50.

https://doi.org/10.1080/00987913.2018.1433906 
Piwowar, Heather; Priem, Jason; Larivière, Vincent; Alperin, Juan-Pablo; Matthias, Lisa; Norlander, Bree; Farley, Ashley; West, Jevin; Haustein, Stefanie (2018). "The state of OA: A large-scale analysis of the prevalence and impact of open access articles". PeerJ, v. 6, e4375.

https://doi.org/10.7717/peerj.4375

Priego, Ernesto (2016). "Signal, not solution: Notes on why Sci-Hub is not opening access". The winnower, v. 5, e145624.49417.

https://doi.org/10.15200/winn.145624.49417

Reichman, Hank (2016). “News: Is it legal?”. Journal of intellectual freedom and privacy, v. 1, n. 2-3, p. 50.

https://doi.org/10.5860/jifp.v1i2-3.6173

Ruff, Corinne (2016). "Librarians find themselves caught between journal pirates and publishers". The chronicle of higher education, 18 February.

https://www.chronicle.com/article/Librarians-Find-Themselves/235353

Russell, Carrie; Sanchez, Ed (2016). "Sci-Hub unmasked: Piracy, information policy, and your library". College \& research libraries news, v. 77, n. 3, pp. 122-125.

https://doi.org/10.5860/crln.77.3.9457

Sathe, Nila A.; Grady, Jenifer L.; Giuse, Nunzia B. (2002). "Print versus electronic journals: A preliminary investigation into the effect of journal format on research processes". Journal of the Medical Library Association, v. 90, n. 2, pp. 235243.

https://www.ncbi.n/m.nih.gov/pmc/articles/PMC100770

Sparc (2018). Big deal cancellation tracking.

https://sparcopen.org/our-work/big-deal-cancellation-tracking

Steel, Graham (2016). "Wallets with a serious case of Stockholm syndrome: Sci-Hub and the future of scholarly communication". The winnower, v. 5, e145677.73287.

https://doi.org/10.15200/winn.145677.73287

Strielkowski, Wadim (2017). "Will the rise of Sci-Hub pave the road for the subscription-based access to publishing databases?". Information development, v. 33, n. 5, pp. 540-542.

https://doi.org/10.1177/0266666917728674

Swartz, Aaron (2008). Guerilla open access manifesto.

https://archive.org/details/GuerillaOpenAccessManifesto

Tenopir, Carol; King, Donald W.; Edwards, Sheri; Wu, Lei (2009). “Electronic journals and changes in scholarly article seeking and reading patterns". Aslib proceedings, v. 61, n. 1, pp. 5-32.

https://doi.org/10.1108/00012530910932267

Travis, John (2016). "In survey, most give thumbs-up to pirated papers". Science news, May $6^{\text {th }}$. https://doi.org/10.1126/science.aaf5704

Triggle, Chris R.; Triggle, David J. (2016). "From Gutenberg to open science: An unfulfilled odyssey". Drug development research, v. 78, n. 1, pp. 3-23.

https://doi.org/10.1002/ddr.21369

Van-Noorden, Richard (2016) “Alexandra Elbakyan: Paper pirate”. Nature, v. 540, n. 7634.

https://doi.org/10.1038/540507a

Woolston, Chris (2016). "Paper piracy sparks online debate". Nature, 2 May.

https://doi.org/10.1038/nature.2016.19841 